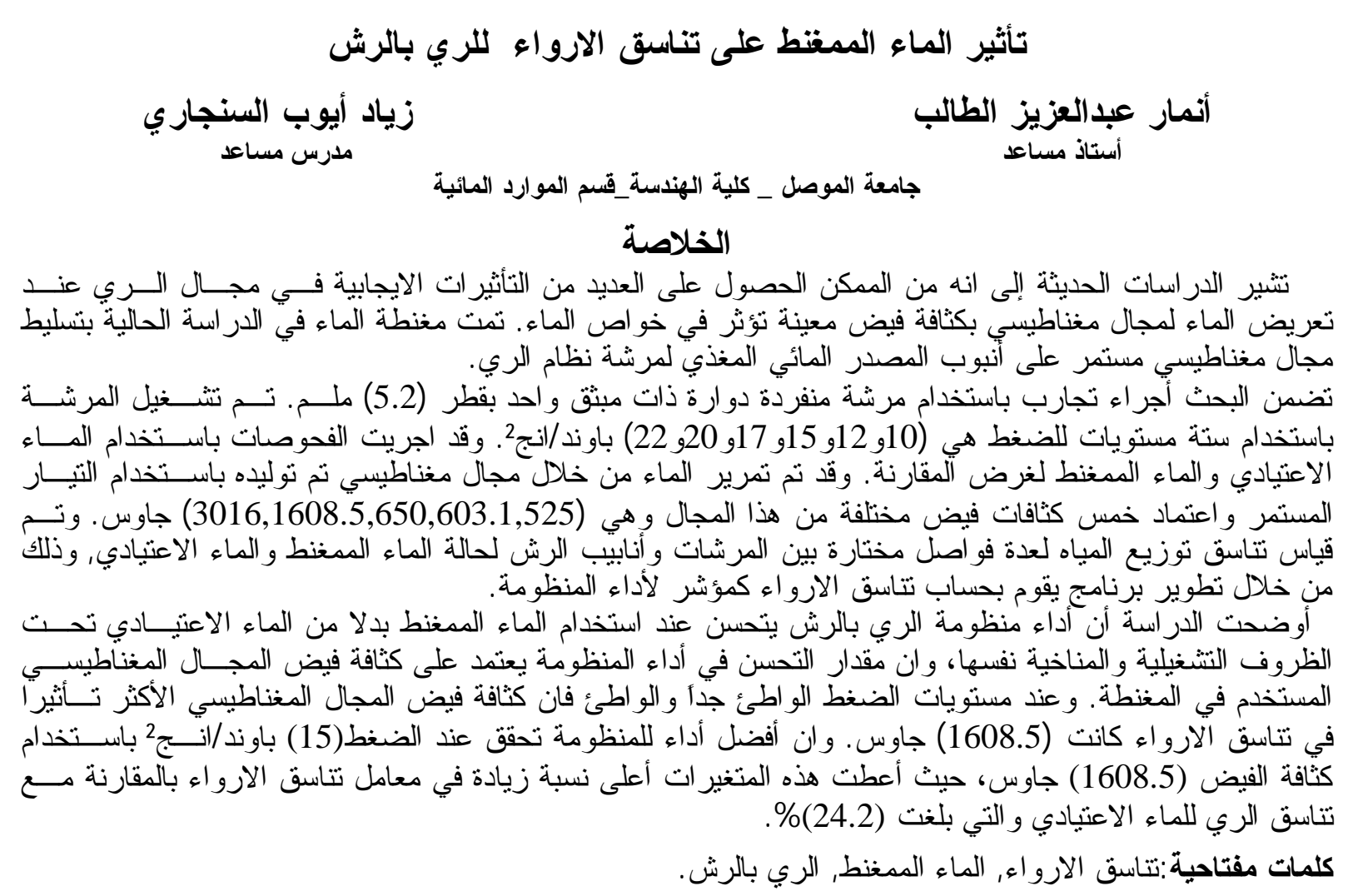

\title{
Effect of Magnetizing Water on Uniformity of Sprinkle Irrigation
}

\author{
Anmar A. AL-Talib \\ Assistant Professor \\ Ziyad A. AL-Sinjary \\ Assistant lecture \\ University of Mosul_ College of Engineering _Water Resources Department
}

\begin{abstract}
Recent researches indicate that if water is exposed to an intense magnetic field, it is possible to obtain many positive effects on water properties that improve water use in irrigation application. Therefore, a field study has been conducted to evaluate the extent of there positive improvements under sprinkler irrigation. Uniformity of sprinkler irrigation is used as a performance indicator under different pressure heads.

The research included experimental work on solid set sprinkler system (single sprinkler type Rain Bird) using rotating sprinkler heads with single nozzle of diameter $5.2 \mathrm{~mm}$. The sprinkler was tested under pressures $(10,12,15,17,20,22)$ psi.

Treatments have been conducted using normal water with 1 to 5 runs. Direct current (DC) magnetic field for magnetizing water is used to magnetize water. Five levels of the DC magnetic flux densities are used $(525,603.1,650,1608.5,3016)$ Gauss.

The study has revealed the performance of the sprinkler irrigation system is improved when the magnetized water is used compared to non-magnetized under the same operating and climatologically conditions. The degree of improvement depends on the intensity of the magnetic field used.Under low and very low pressures, the most effective intensity on uniformity was the intensity 1608.5 Gauss . The best performance of the system was achieved at (15) psi with direct magnetic flux density of 1608.5 Gauss. There variables have achieved the highest increase in irrigation uniformity compared with irrigation in normal water which was $24.2 \%$.
\end{abstract}

Key Words: uniformity of irrigation, magnetized water, sprinkler irrigation. 


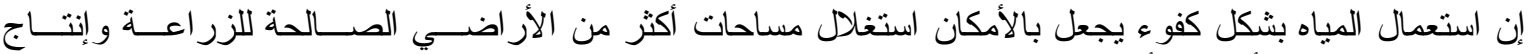

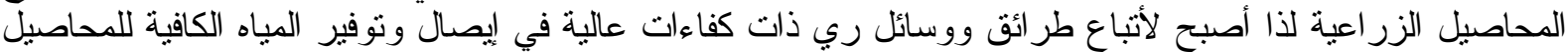

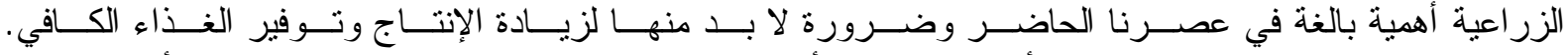

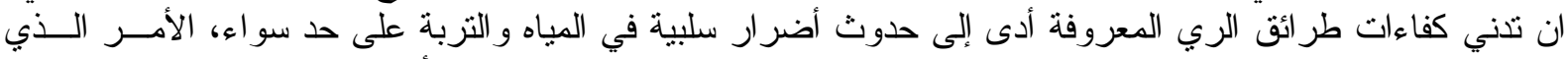

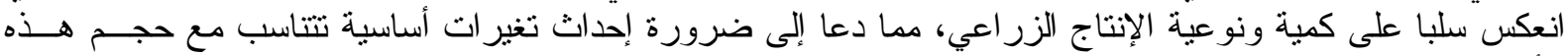

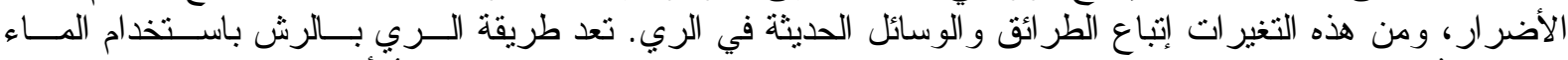

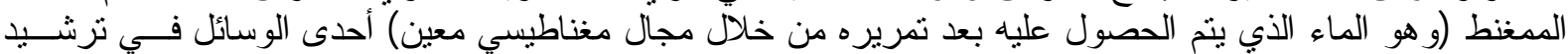

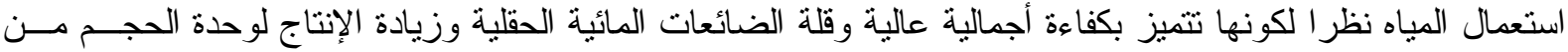

الماء [1].

تقل فو اقد رذاذ الرش عند استخدام الماء الممغنط كبديل عن الماء الاعنيادي تحت ظروف تشغيلية وعوامل مناخية

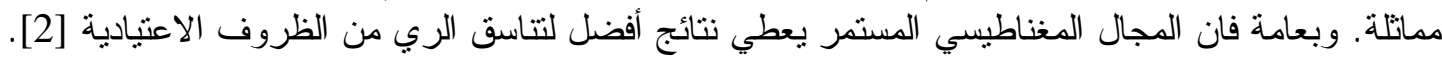

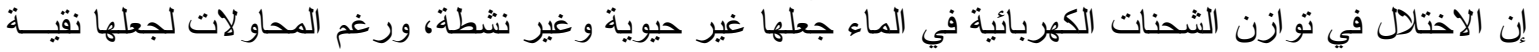

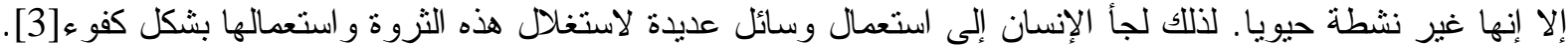

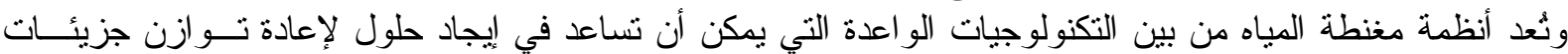

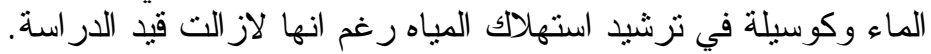

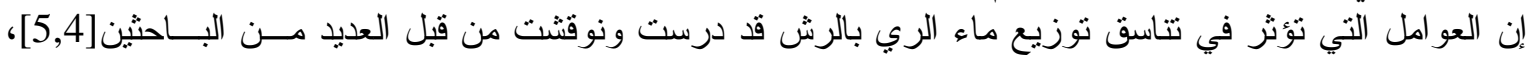

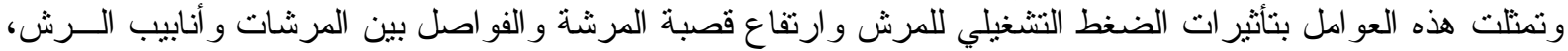

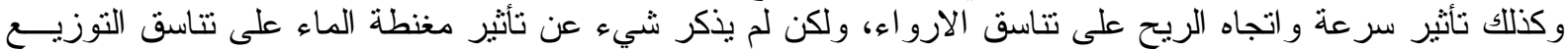

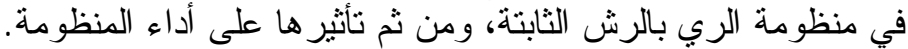

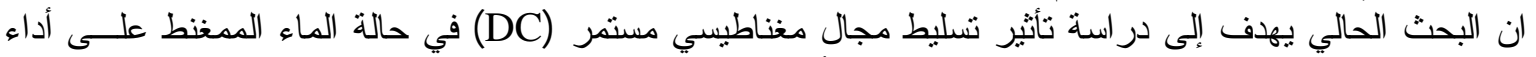

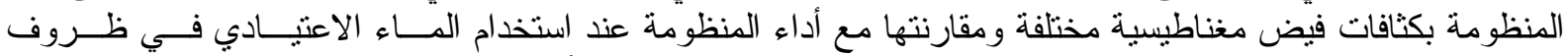

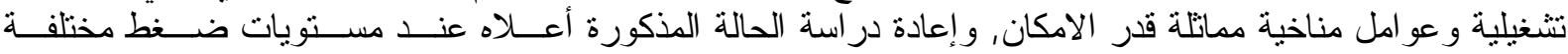
وباستخدام قطر ثابت لفو هة المرشة.

\section{تأثير المجال المغناطيسي على شكل جزيئة الماء}

بعامة تتكون جزيئة الماء من ذرة أوكسجين وذرتي هيدروجين، ذرات الهيدروجين في جزيئة الماء الواحدة تجتنب

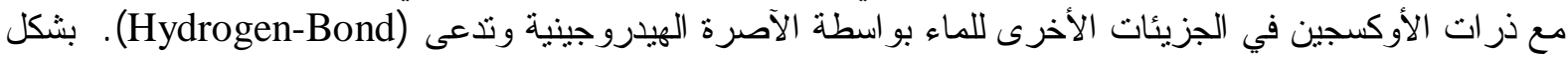
عام، في جزئية الماء ذرة الأوكسجين وذرتي الهيدروجين مرتبطان كمنلث متساوي الساقين (isosceles triangle)، و الزاوية العليا له 105.03 درجة، لذا فان الثنكل ألجزيئي للماء كما هو مبين في في الثكل (1)[6]. شكل (1) الثكل الجزيئي للماء.

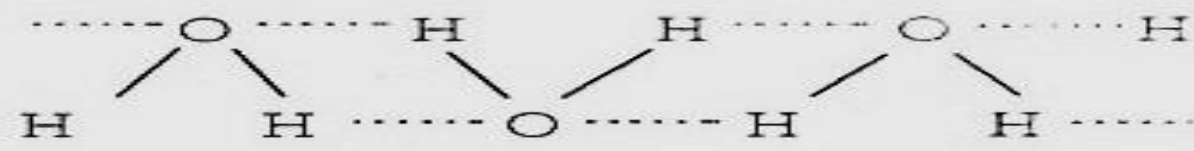

عندما يمرر الماء من خلال مجال مغناطيسي بكثافة فيض معينة فان جزيئات الماء تتوجه في اتجاه و احــد، كمــا هــو

مبين في الثنكل (2).

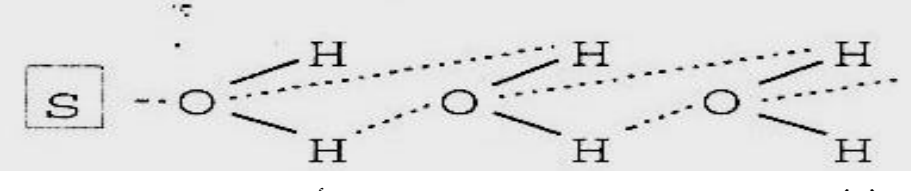

شكل (2) الترتيب الموجه لجزيئات الماء تحت تأثير المجال المغناطيسي. 


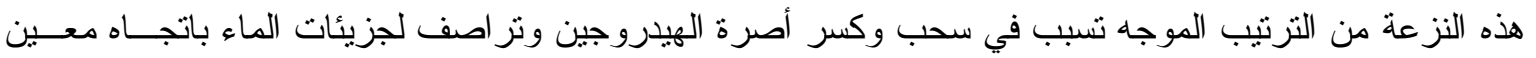

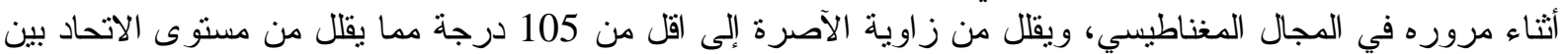

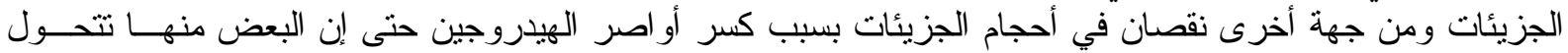

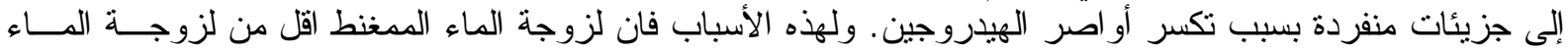

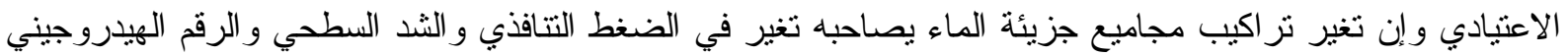

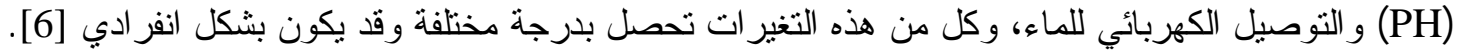

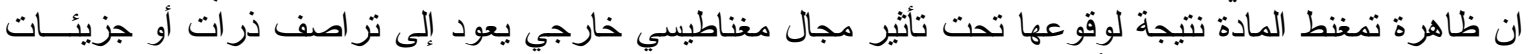

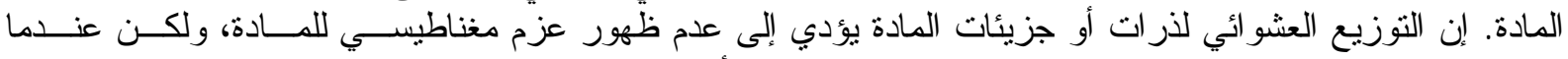

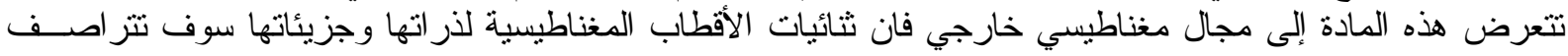

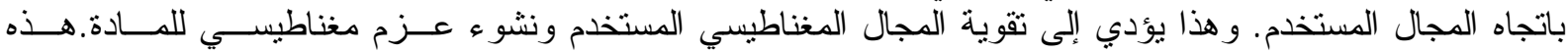

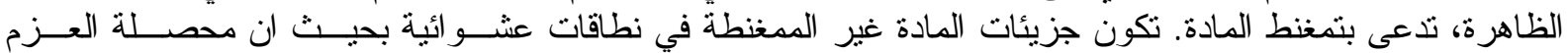

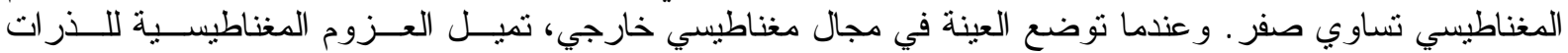

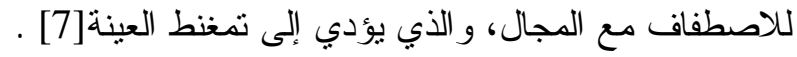

\section{الأدوات و الأجهزة المستخدمة في العمل}

تم إجر اء التجارب الحقلية باستخدام الأدوات و الأجهزة الآتية:

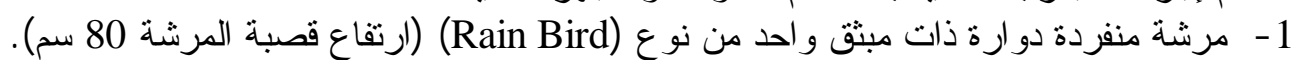

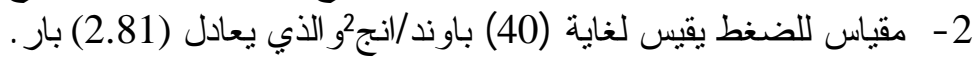
3 - علب تجميع الماء (catch cans) من (50 - 120) علبة (اعتمادا على قطر المســاحة المبلولــة و أبعـاد وحهـدة (التشبيك).

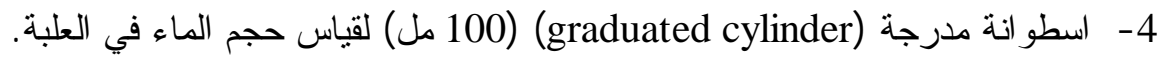

5 - 5 - مضخة ماء (water pump) لضخ الضخ الماء من المصدر (إلى المرشة.

6 - 6 - أنبوب نقل ماء بلاستيكي بقطر نصف (Dav)

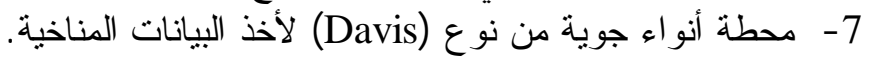

8 - 8 - ساعة توقيت.

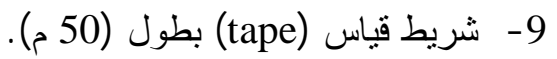

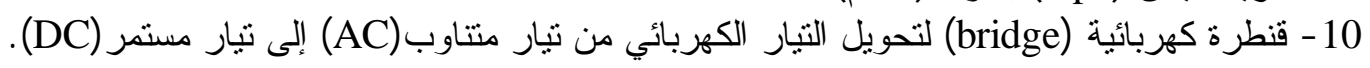

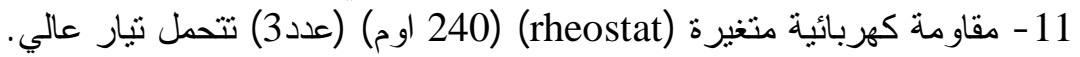

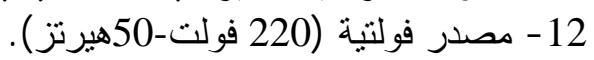

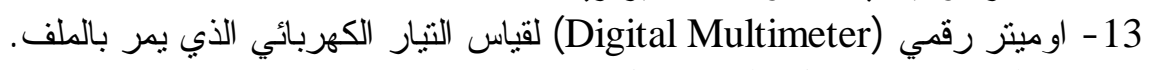

14 - اسطو انات زجاجية لخفظ نماذج الماء.

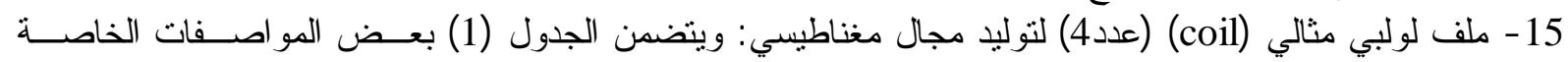

بالملفات المستخدمة في توليد المجال المغناطيسي ليدي

الجدول (1):- مو اصفات الملفات المستخدمة في التجارب.

\begin{tabular}{|c|c|c|c|c|c|c|}
\hline المغنافة الفيضي المستمر & 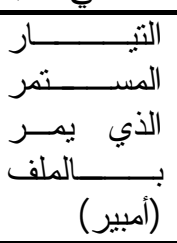 & 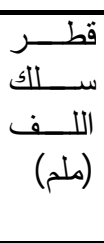 & 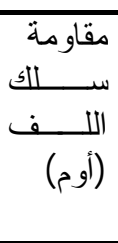 & 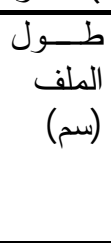 & عدد اللفات & رلملف \\
\hline 3016 & 1.2 & 0.2 & 135 & 10 & 20000 & -1 \\
\hline 1608.5 & 1.0 & 0.2 & 135 & 12.5 & 16000 & -2 \\
\hline 650 & 1.35 & 0.6 & 125 & 15 & 5700 & -3 \\
\hline 603.1 & 1.2 & 0.6 & 125 & 22.5 & 9000 & -4 \\
\hline 525 & 1.1 & 0.6 & 125 & 15 & 5700 & -5 \\
\hline
\end{tabular}




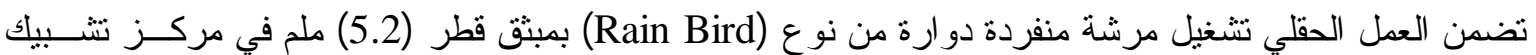
(grid)

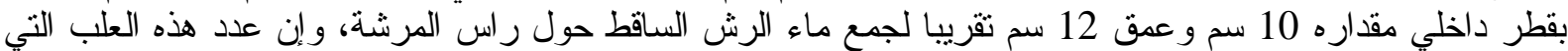

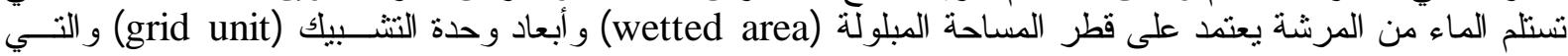

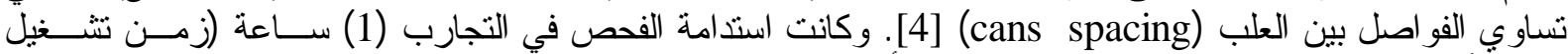

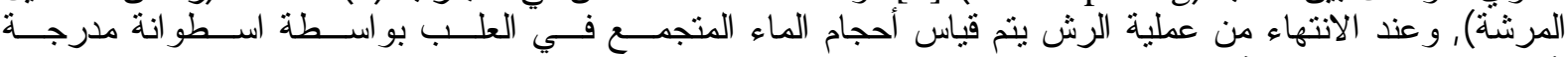
. (graduated cylinder)

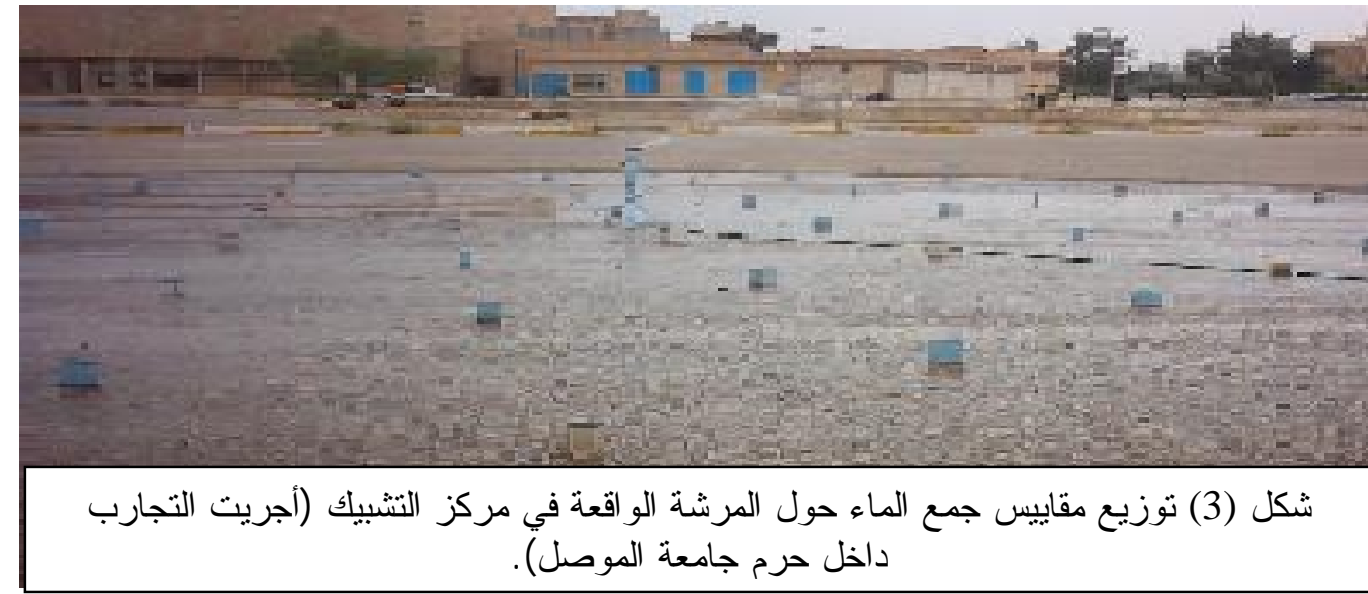

شملت التجارب تتغيل المرشة تحت ست مستويات للضغط التشغيلي هي (22,20,17,15,12,10)باوند/انج2. و وعند

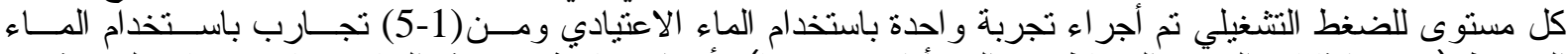

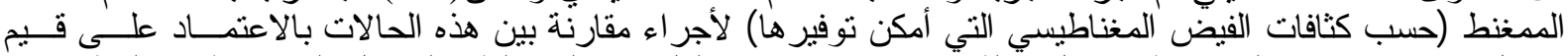

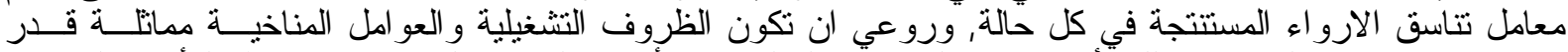

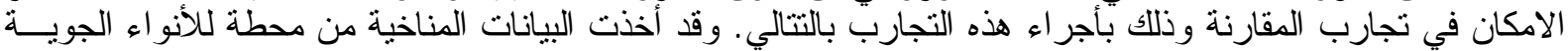

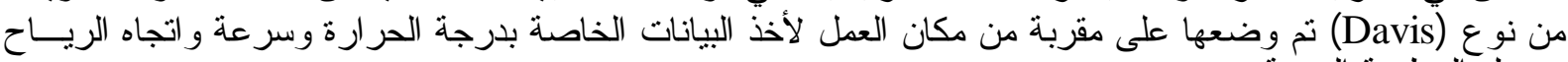

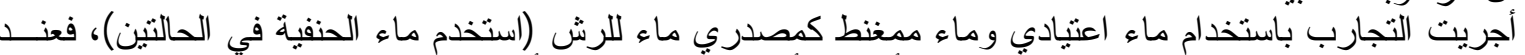

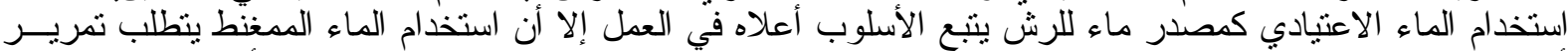

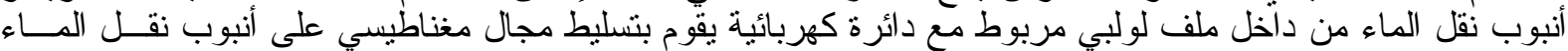

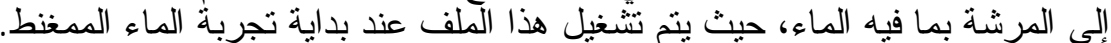

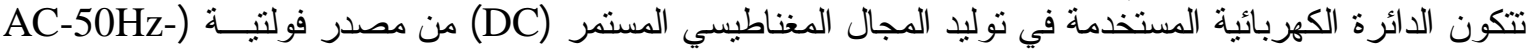

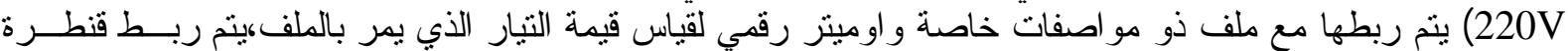

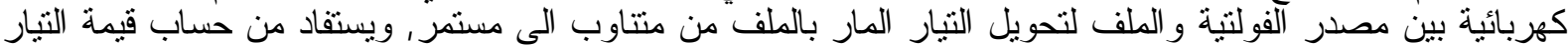
في معرفة كثافة فيض المجال المغناطيسي المستمر الذي يمر بالملف.ومبين شئل شئل هذه الدائرة في الثكل (4).

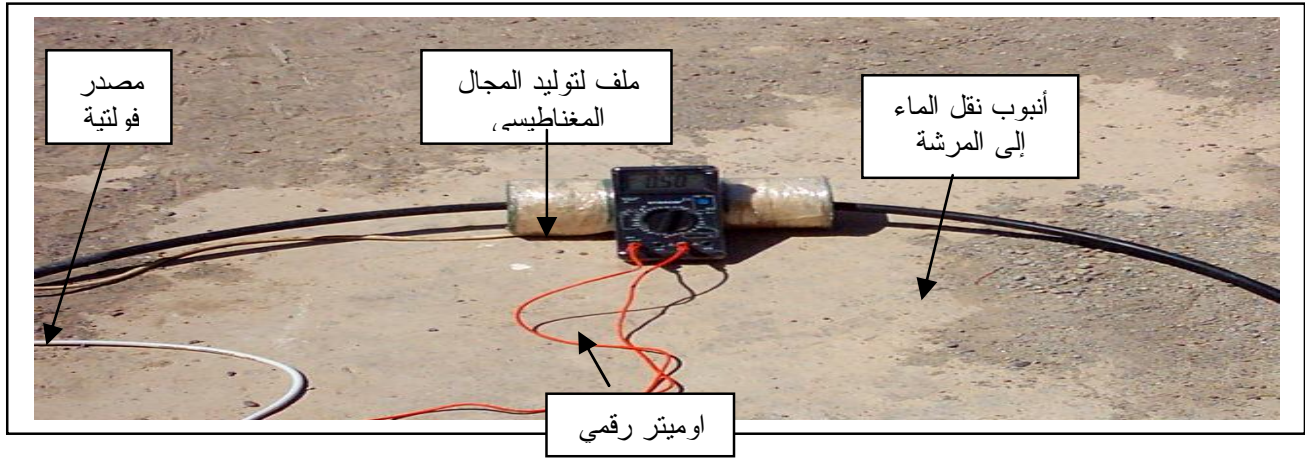

شكل (4) الدائرة الكهربائية المستخدمة في توليد المجال المغناطيسي المستمر . بعد الانتهاء من كل تجربة تتبت البيانات في جداول خاصة أثناء العمل و المبين نموذج منه في الجدول (2). 


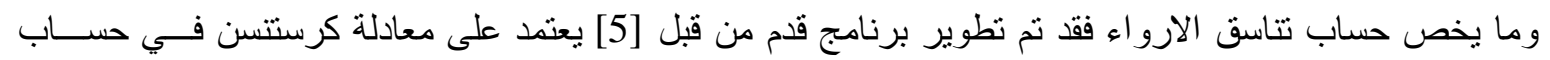
التناسق. ويمثل المخطط (1) المخطط العام للتجارب الحقلية التي اجريت في في فذا فئ البحث.

الجدول (2):- بيانات أحجام ماء الرش باستخدام الماء الممغنط

نوع المجال المغناطيسي: مستمر المغيط شدة المجال المغناطيسي: 525 جاوس المناط تصريف المرشة: 0.991 مُ3/سا الريا

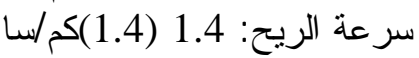

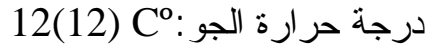

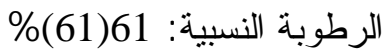

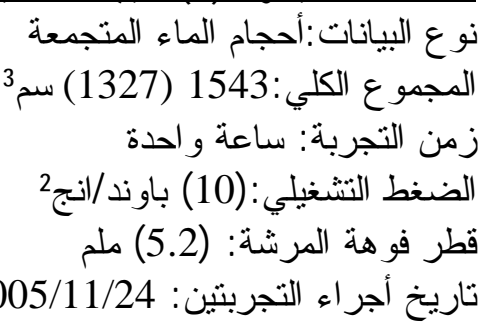

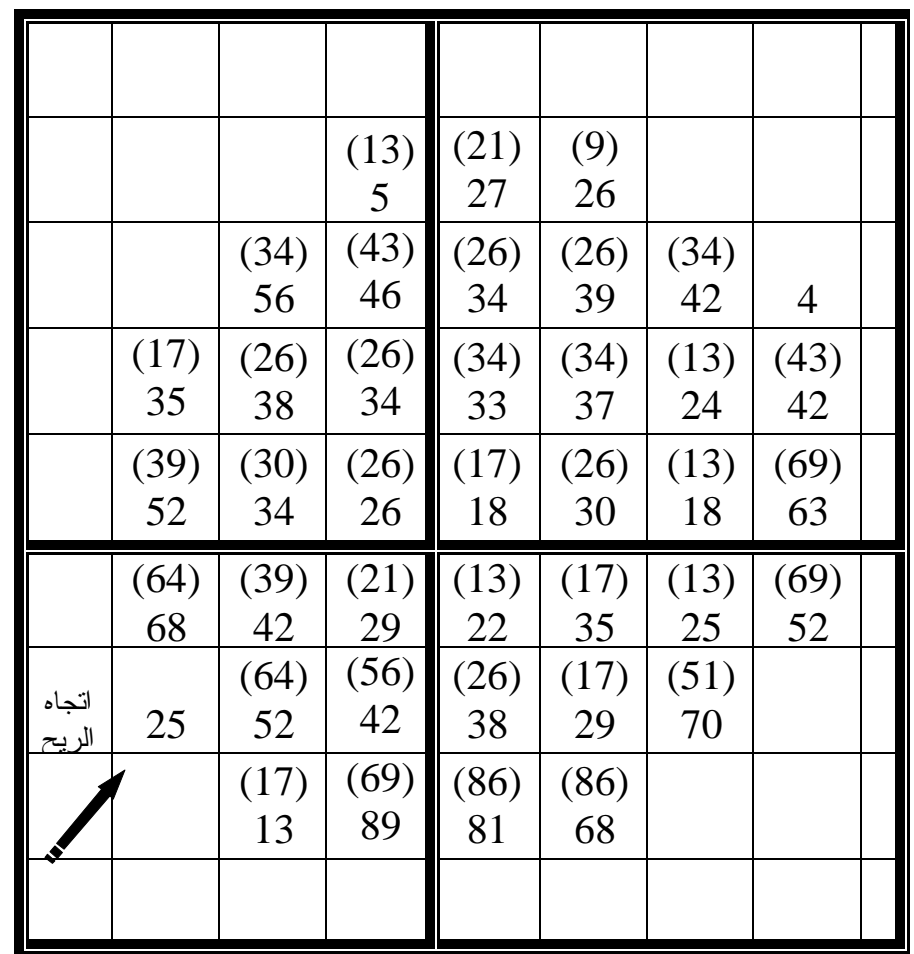

*الأرقام الموجودة بين قوسين تمثل البيانات الخاصة بتجربة الماء الاعتيادي.

يمكن استعمال قانون امبير لحساب كثافة الفيض المغناطيسي داخل ملف لولبي وكالاتي [8]: $\vec{B}=\mu 。 \frac{N * I}{L_{c}}\left(a_{\text {axis }}\right)$

$$
\text { اذ أن: المجال المغناطيسي (تسلا) أو (ويبر / متر2). }
$$

。 =I =N = عدد اللفات الكلية في الملف في لالفي . طول الملف (منر) 


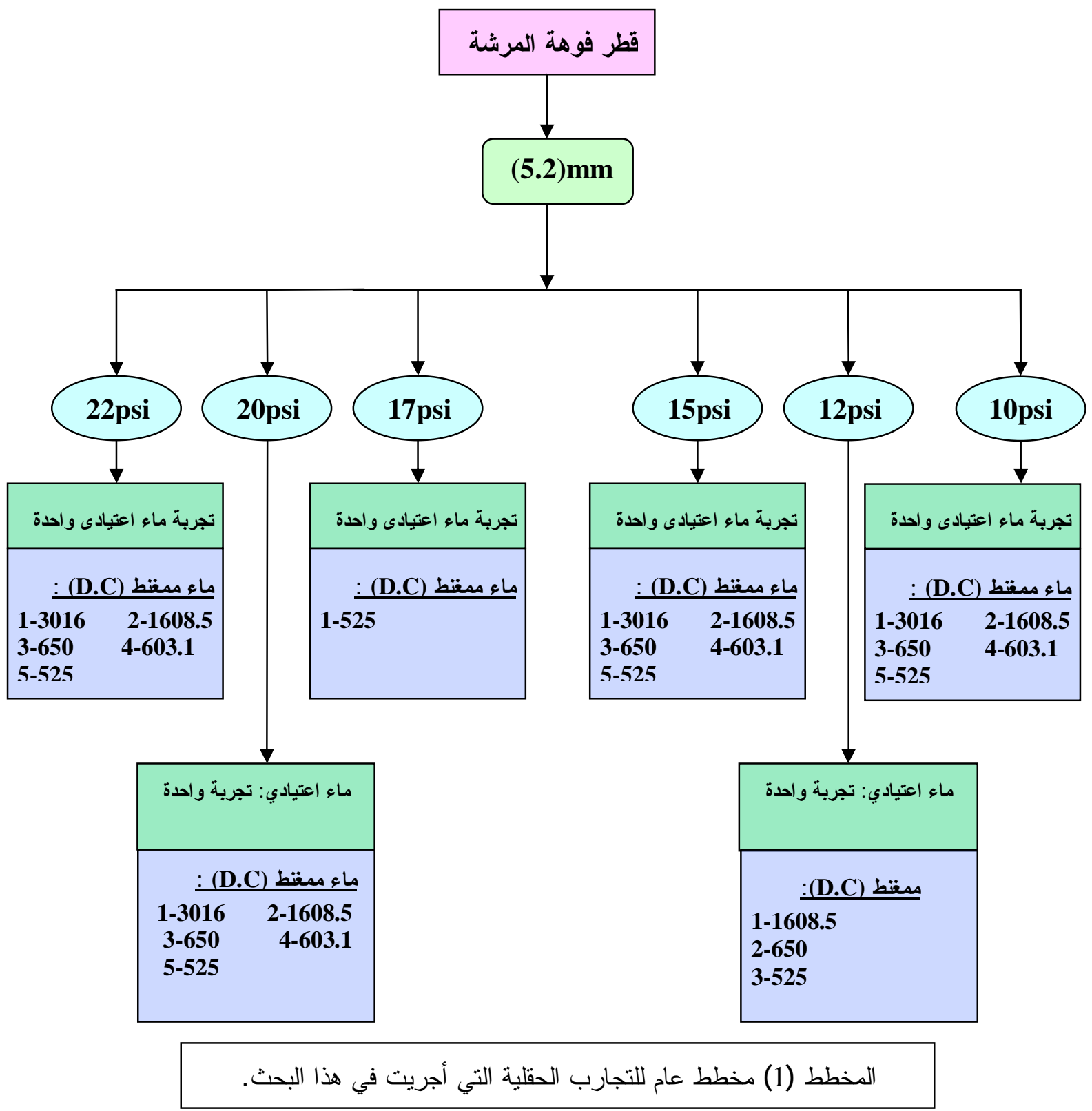

\section{النتائج والمناقشة}

1 - تناست الارواء باستخدام الماء الممغتط و الاعتيادي: -

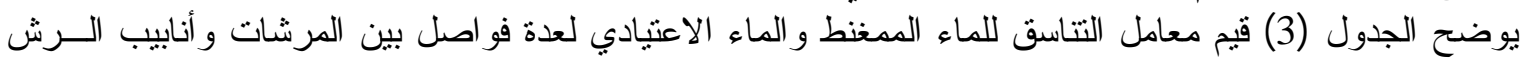

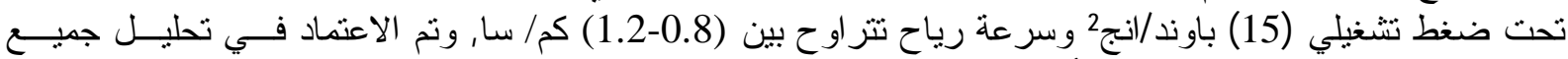

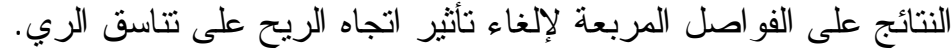

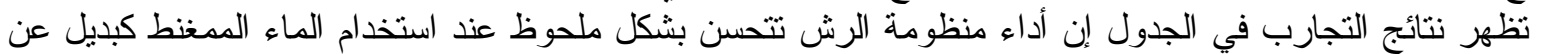

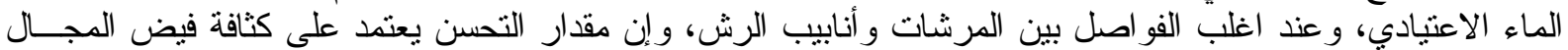

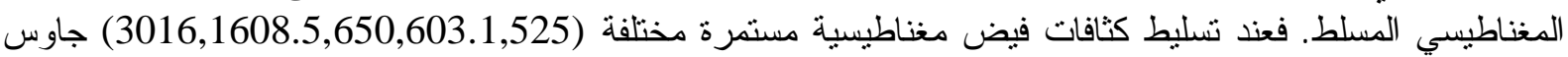

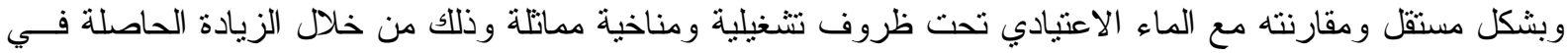

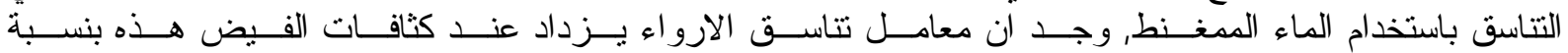

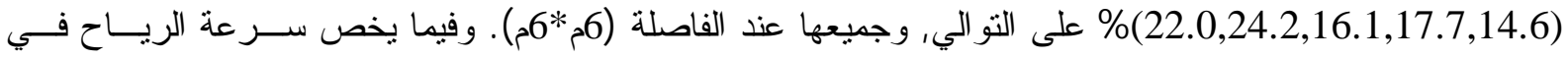


التجارب المثبتة في الجدول (3) ، فقد كانت منقاربة من حيث السرعة لذلك فأنها لا تؤثر في عملية المقارنة بـين قـيم معامل التناسق.

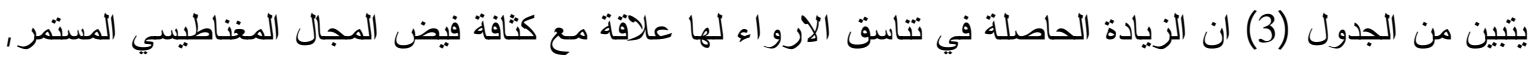

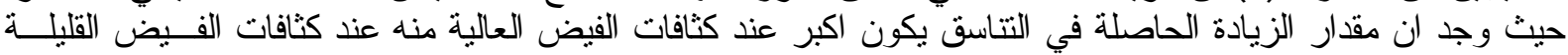

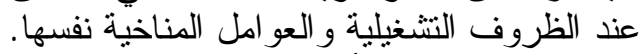

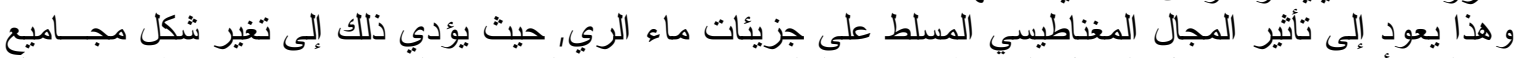

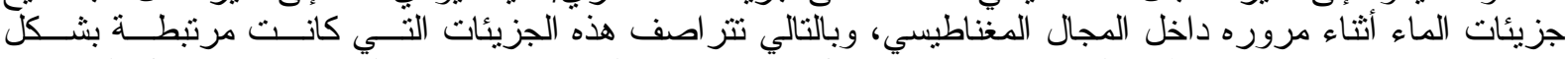

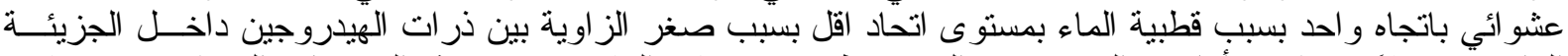

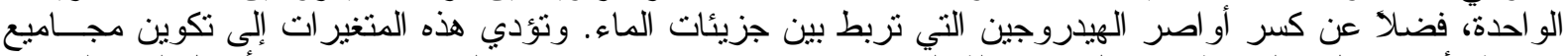

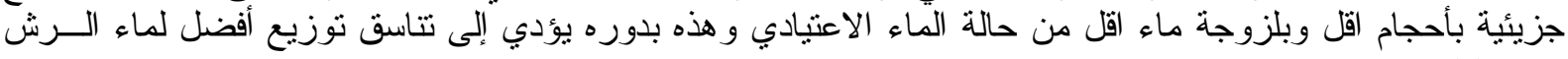
. $[11,9,6]$

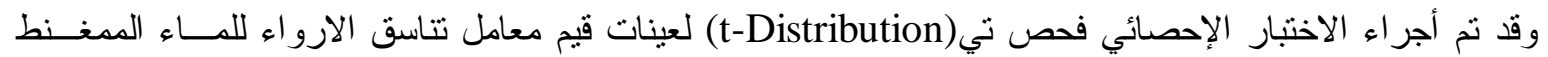

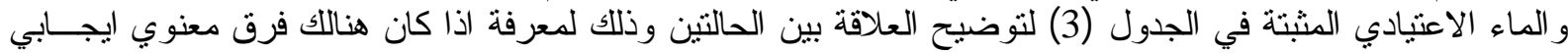

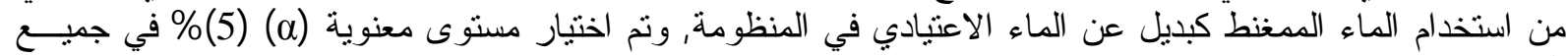

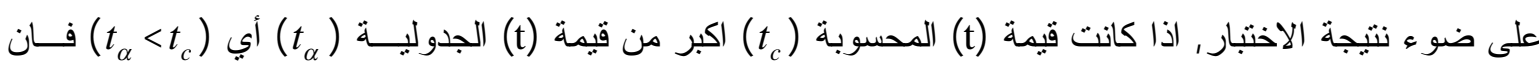

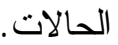

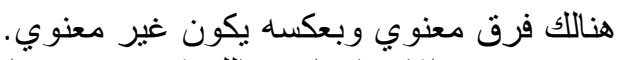

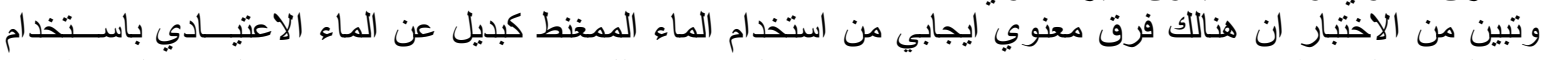

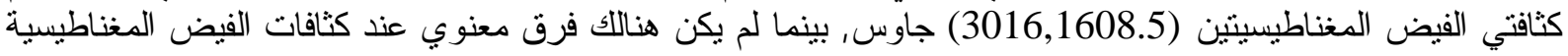
(650,603.1,525)

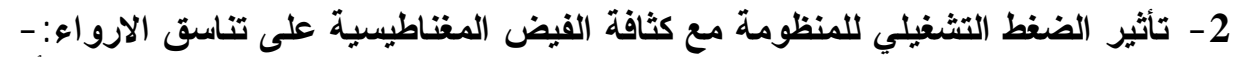

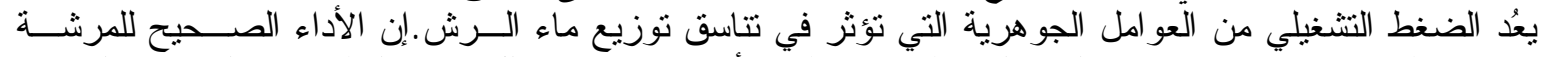

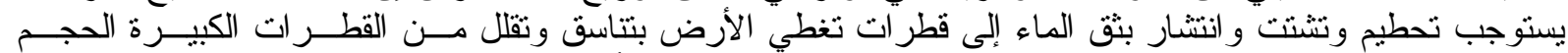

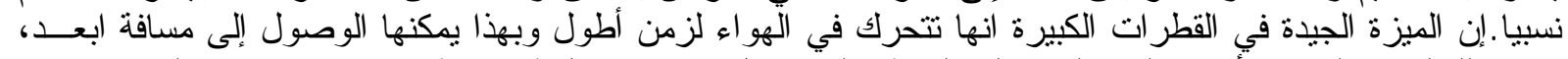

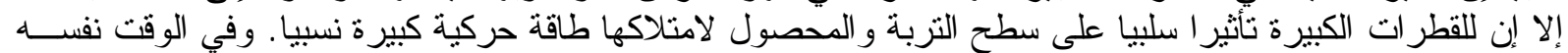

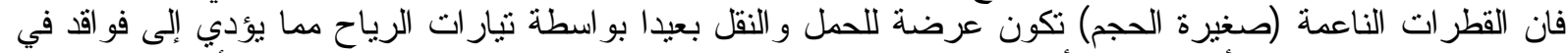

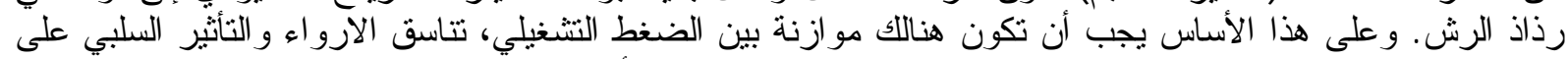

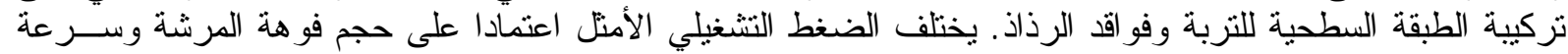

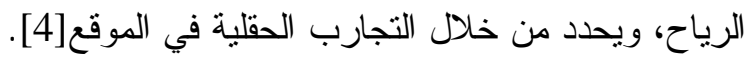
صنفت جمعية الري الأمريكية (AIA) حسب [10] أنظمة الري بالرش إلى ثلاثة مجاميع رئيسة اعتمادا على الضــــ

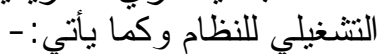

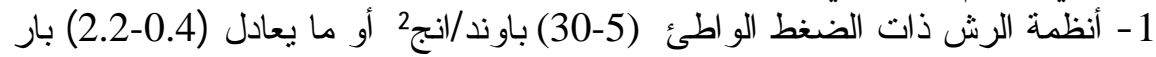

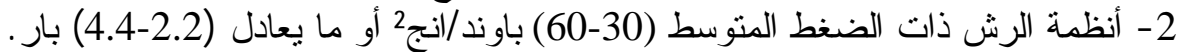

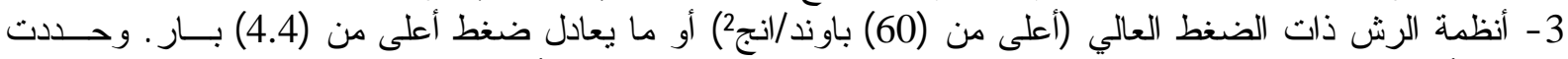

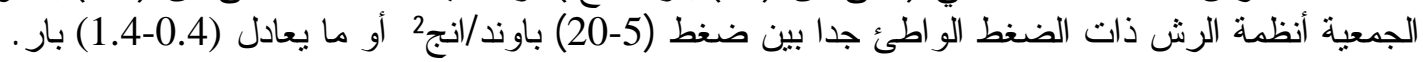

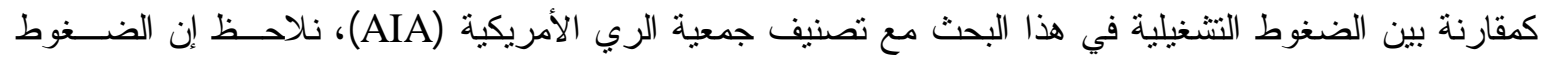

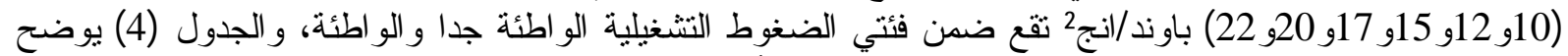

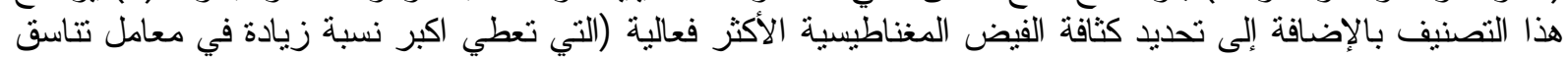
الارو اء مقارنة مع الماء الاعنيادي) عند كل ضغنط. 


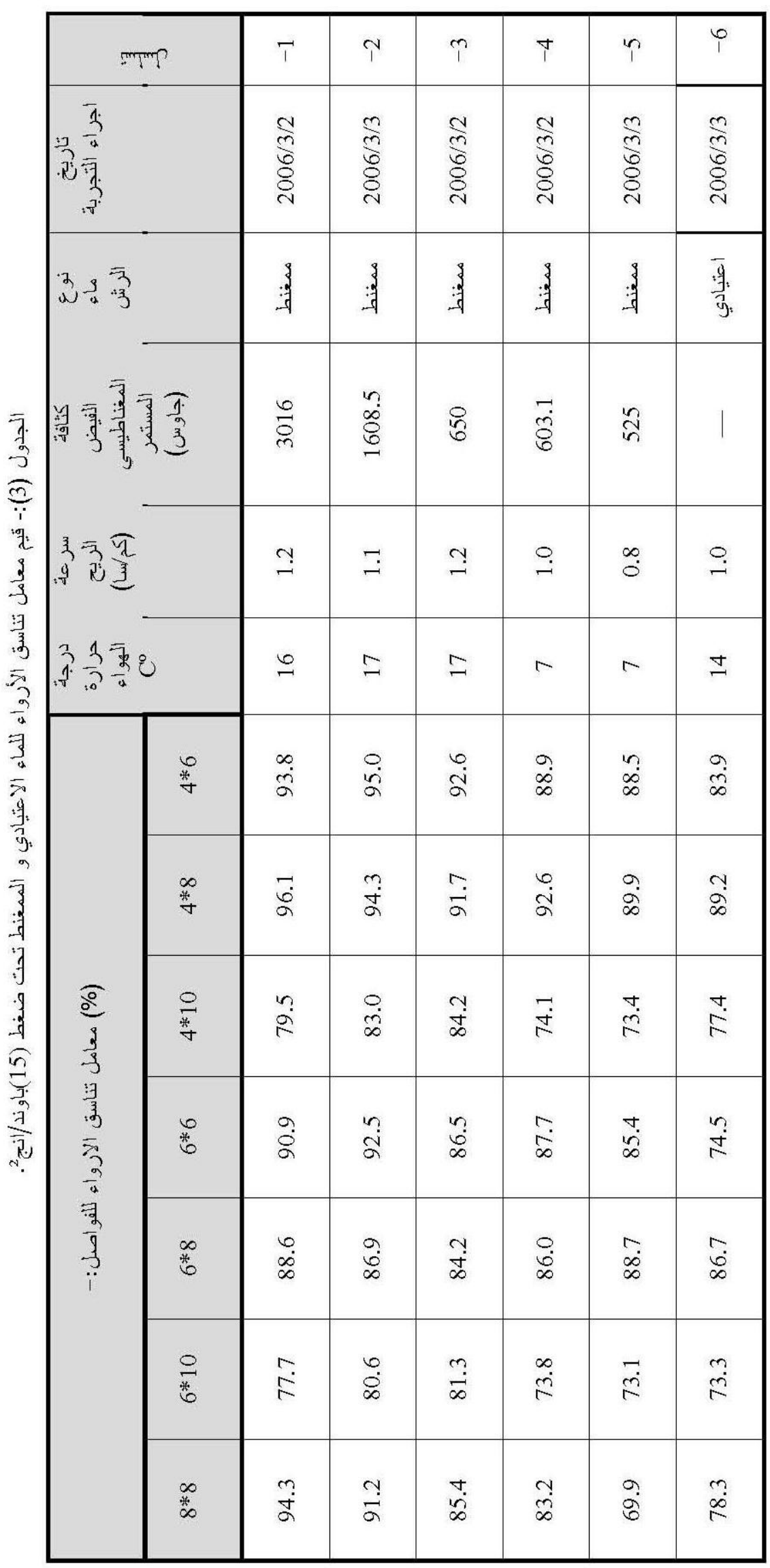


الطالب : تأثير الماء الممغط على تناسق الارواء للري بالرش

الجدول (4):- صنف الضغط التشغيلي وكثافة الفيض المغناطيسية الأكثر فعالية لديه.

\begin{tabular}{|c|c|c|c|c|c|c|}
\hline التهاصلة & الزئيادة & الألثيض & كثافات الفيض هذا الضناطيسية المسلطة & الضنف & باوندانغيلي & 㝵 \\
\hline $8 * 8$ & 18.3 & 1608.5 & $525,603.1,650,1608.5,3016$ & و اطئ جدا & 12 & -1 \\
\hline $6 * 6$ & 24.2 & 1605.8 & $525 ، 603.1 ، 650 ، 1608.5 ، 3016$ & و اطئ جدا & 15 & -2 \\
\hline $6 * 6$ & 10.4 & 525 & 525 & و اطئ جدا & 17 & -3 \\
\hline $8 * 8$ & 14.8 & 3016 & 525،603.1،650،1608.5،3016 & و اطئ جدا & 20 & -4 \\
\hline $10 * 10$ & 22.0 & 1608.5 & 525،603.1،650،1608.5،3016 & و اطئ اطئ & 22 & -5 \\
\hline
\end{tabular}

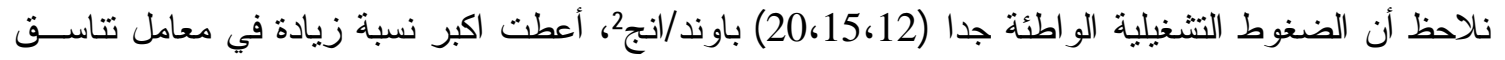

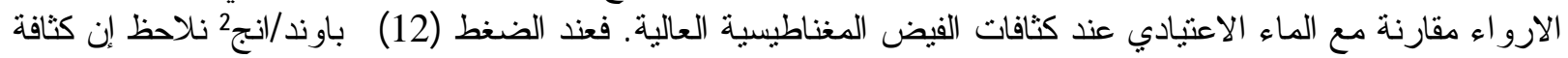

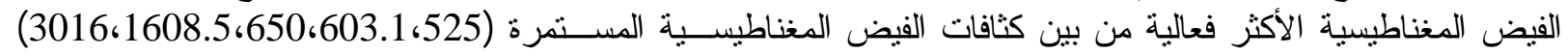

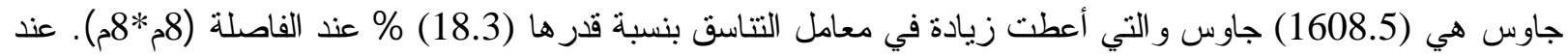

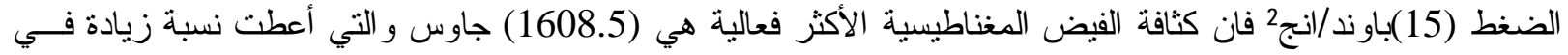

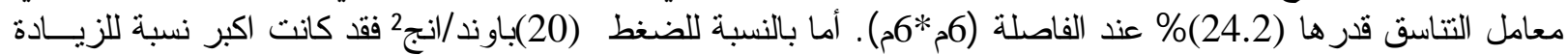
عند أعلى كثافة فيض مغناطيسية مستخدمة.

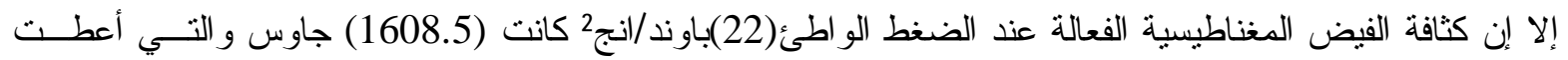

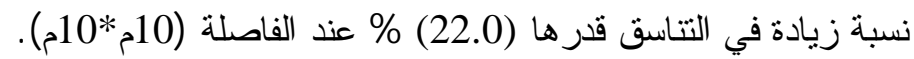

إعامة تبين ان المجال المغناطيسي المستمر ذو الكثافة (1608.5) جاوس ذو تأثنير ايجابي كبير في معامل التناسق عند

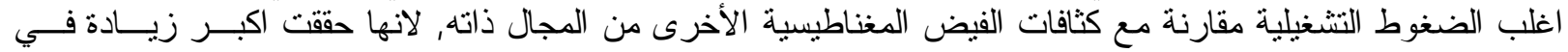

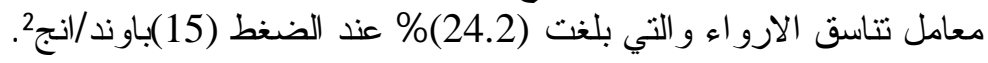

3 - الجدوى الاقتصادية من استخدام الماء الممغنط في منظومات الرش الثابتة: -

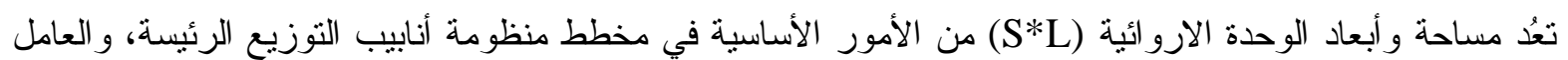

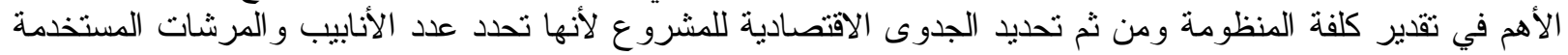
في المنظومة.

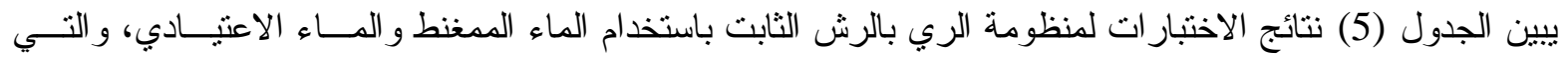

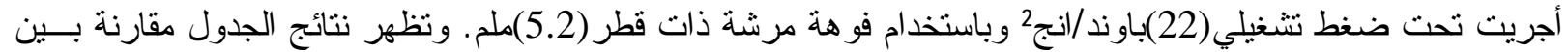

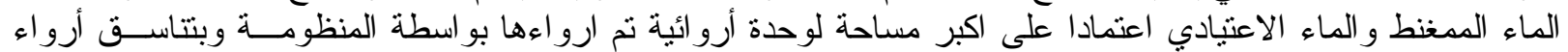
مقبول ( أكبر من 80\%)، وقد تم مغنطة الماء أماء باستخدام كثافات فيض مغناطيسية مستمرة مختلفة. 
الجدول (5):- مساحة الخدمة بين المرشات للماء الممغنط و الاعتيادي عند ضغط (22)باوند/انج2.

\begin{tabular}{|c|c|c|c|c|c|c|c|}
\hline 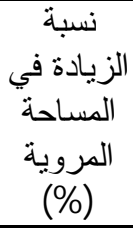 & 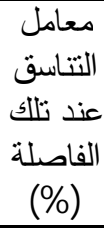 & أعطاصلة التير & مبتر مروية & المثناطيسي الفيضي & ماء الرش & التجربة اء & 号 \\
\hline 87.5 & 81.5 & $10 * 12$ & 120 & 3016 & ممغنط & 2006/8/7 & -1 \\
\hline 87.5 & 86.7 & $10 * 12$ & 120 & 1608.5 & ممغنط & 2006/8/7 & -2 \\
\hline 87.5 & 85.5 & $10 * 12$ & 120 & 650 & ممغنط & $2006 / 8 / 7$ & -3 \\
\hline 87.5 & 83.8 & $10 * 12$ & 120 & 603.1 & ممغنط & $2006 / 8 / 6$ & -4 \\
\hline 12.5 & 81.9 & $6 * 12$ & 72 & 525 & ممغنط & $2006 / 8 / 6$ & -5 \\
\hline- & 84.0 & $8 * 8$ & 64 & - & اعتيادي & $2006 / 8 / 6$ & -6 \\
\hline
\end{tabular}

وبذلك فقد اعتمد على مساحة و أبعاد الوحدة الاروائية في عمل مقارنة اقتصادية بين منظومة رش ثابتة باســتخدام المــاء

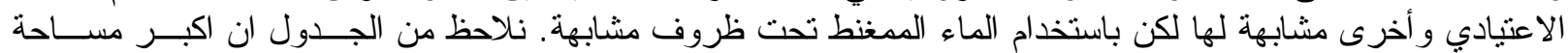

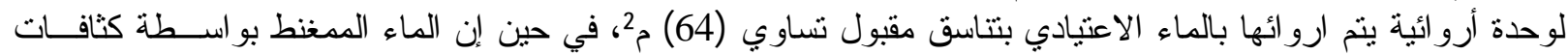

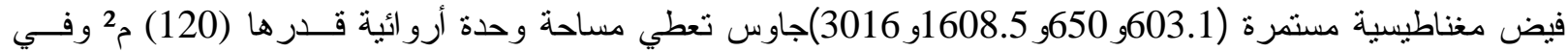

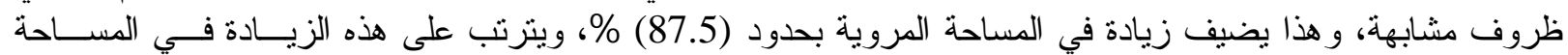

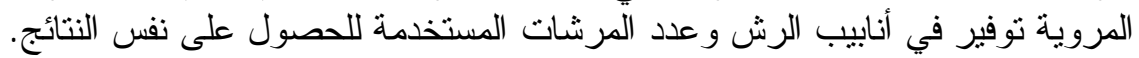

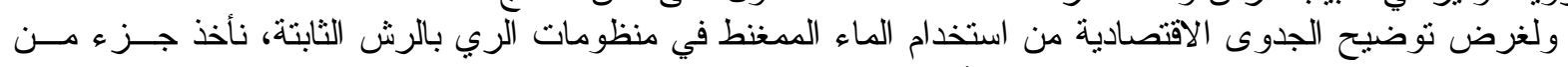

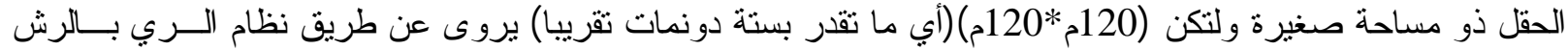

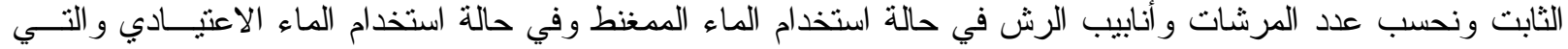

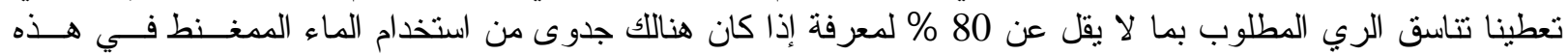

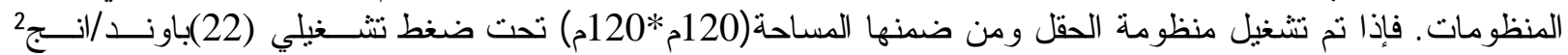

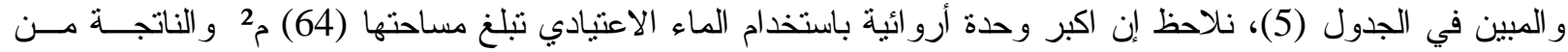

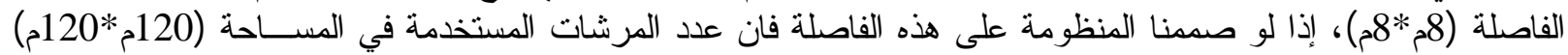

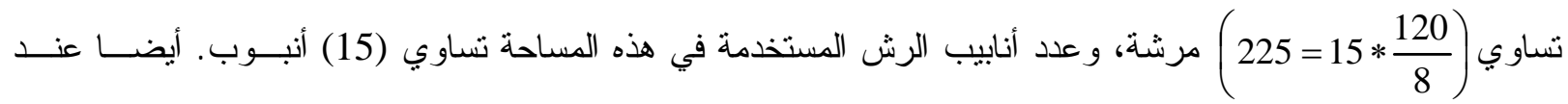

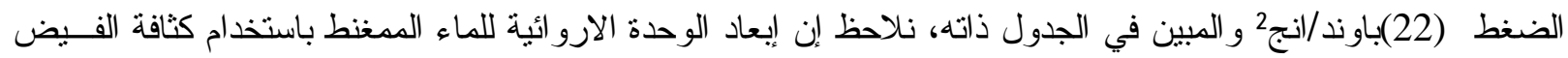

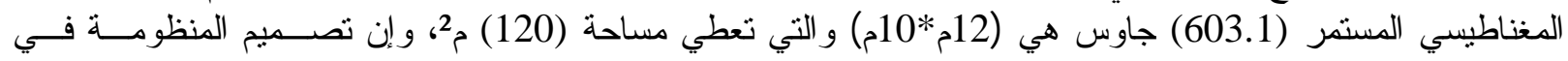
المساحة (120م*120م) على هذه الفاصلة تتطلب (10 10 * 10 = 120) مرشة، بالإضافة إلى (10) أنابيب رش.

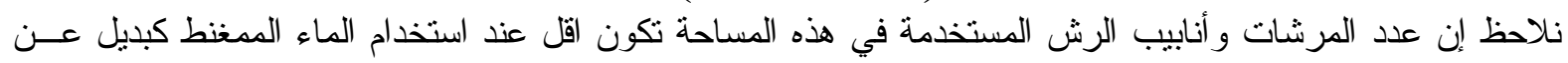

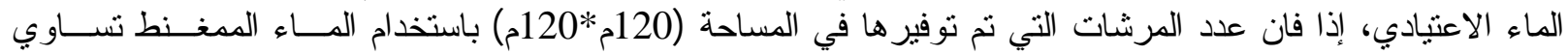

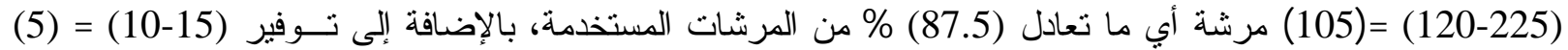

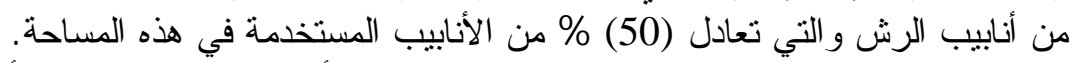

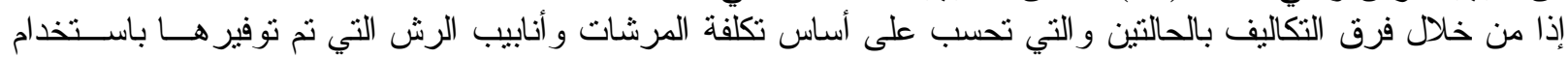

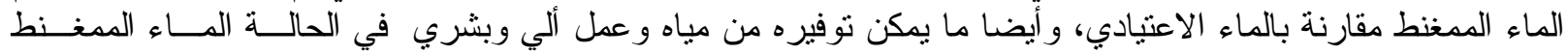

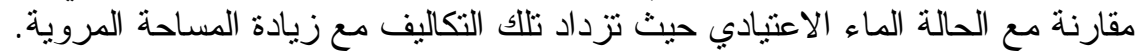


الاستنتاجات

تحت ظروف ومحددات اجر اء التجارب في هذا البحث يمكن تثبيث ايجابية التي تم التوصل إليها في هذا البحث بمـــا

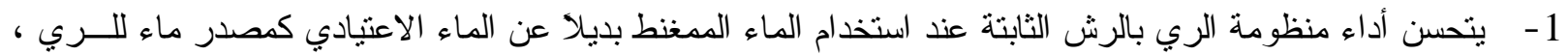

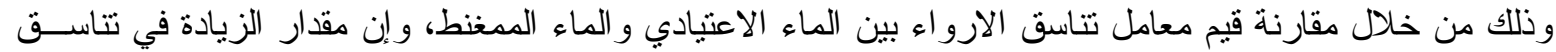
الارواء يعتمد على كثافة الفيض المغناطيسية المستخدمة.

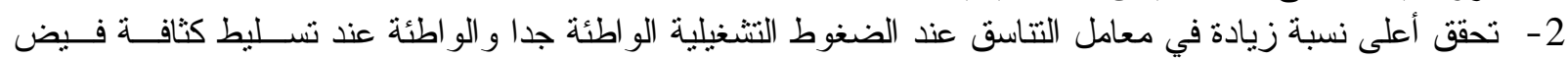

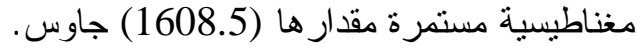

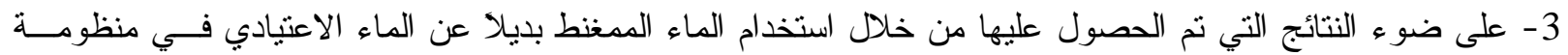

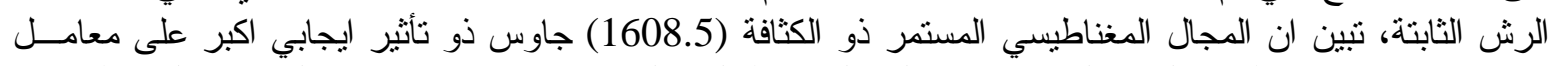

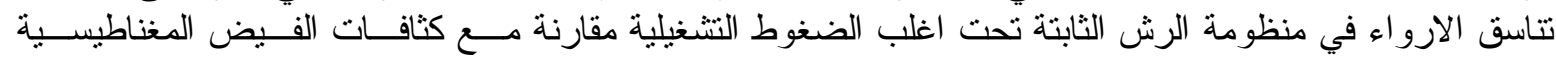

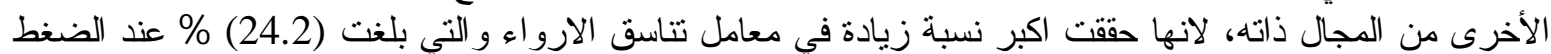

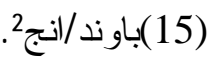

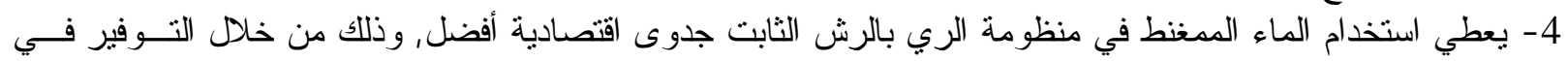

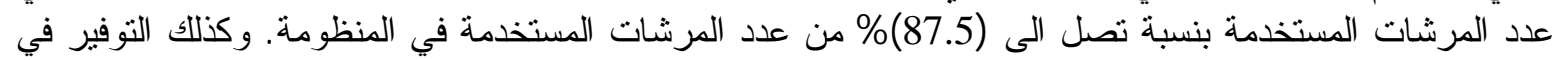

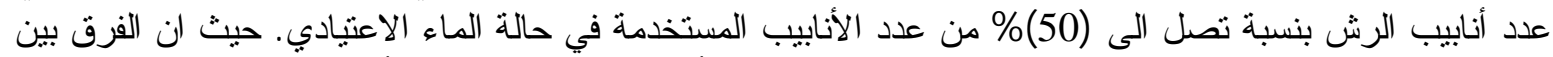

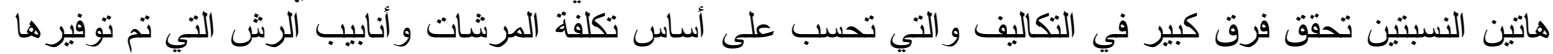
باستخدام الماء الممغنط مقارنة بالماء فئن الاعنيادي.

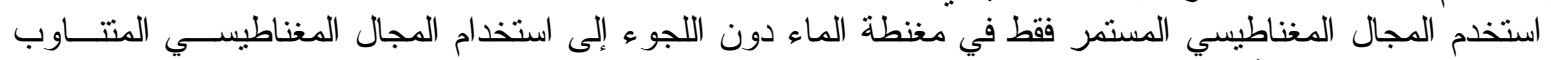

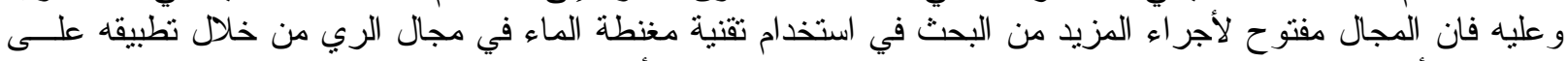

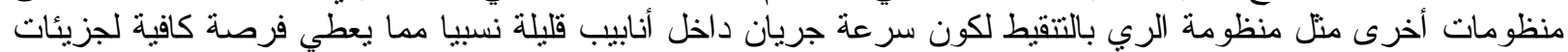

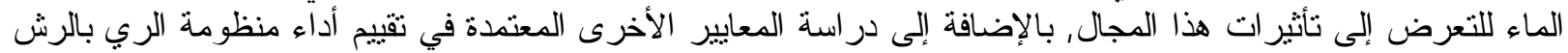
مثل الكفاءة (فو اقد رذاذ الرش) لما يحدثه المجال المغناطيسي المسلط من تغير ات في حجم قطر الات الرش.

1- Hilal, M. H. "Application of Magnetic Technologies in Desert Agriculture Seed Germination and Seedling Emergence of some Crops in A saline Calcareous Soil" Prof. Dr., National Research Helal, M.M.M.Sc., Engineering,R\&D Center, Cairo R\&D Department Head, Giza Department Technology, 2000.

2- السنجاري, زياد أيوب, تأثثير الماء الممغنط في تتاسق الارواء لمنظومة الري بالرش الثابتة, رسالة ماجسـتير, كليــة

$$
\text { الهندسة, جامعة الموصل,2007. }
$$

3 - تكانتينكو، يوري، و أوجلي, جمعة خامرو . ,البيئة, شركة التقنيات المغناطيسية، فرع دبي_ الإمار ات العربية. ســنة .2002

(Yahoo Search: magnetic technologies (arabic language))

4 - حاجم، احمد يوسف، و ياسين ,حقي إسماعيل ,الري الحقلي, دار الكتب للطباعة و النشر، جامعسـة الموصـل، ســـنة .1992

5- Jajjo, N. M. "Water Distribution Under Stationary Sprinkler Irrigation System" M.Sc. Thesis , College of Engineering, University of Mosul,1981. 
6- Fluid Energy Australia. " The Mechanism of the Vortex Water Energy System" Helping Agriculture \& the Environment through the $21^{\text {st }}$ Century, Stafford Lowe,2001.

7 - القيسي، غازي ياسين. , الكهربائية و المغناطيسية, دار المسيرة للنشر و التوزيع و الطباعة، الطبعــة الأولـى، عــــان -

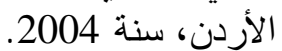

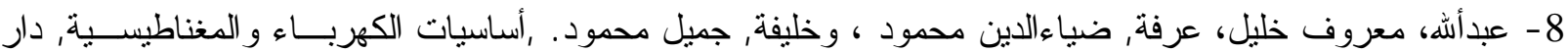
المناهج للطباعة و النشر ، عمان - الأردن، سنة 2002.

9-Chhatwani, P." Magnetized Water" (Email: pjan86@yahoo.com), (Yahoo Search: magnetized water) ,2005

10- Dawood, A. F. "Evaluation of Commercial Low Pressure Sprinkler" M.Sc Thesis, College of Engineering, University of Utah, Logan, Utah. 1982.

11- Magnetic Therapy Council . "Magnetic Water" www.magnetictherapyfacts.org,2006.

$$
\text { تم اجراء البحث في كلية الهندسة - جامعة الموصل }
$$

